\title{
Welcome to The Critical Social
}

\section{Educator}

\section{Dear Readers,}

As we considered what we wanted to focus on in our first issue, it became obvious that we needed to start at the beginning. If we called this space The Critical Social Educator, what did we mean by a "critical social educator"? In particular, how do classroom teachers, researchers, and others understand what it means to be critical?

This isn't just an esoteric or philosophical question. Throughout the world, young children (birth-12 years of age) experience social trauma and oppression on a daily basis within their schools and communities. This includes exposure to racism, sexism, homophobia, transphobia, economic inequality, xenophobia, ableism, anti-Semitism, Islamophobia, climate change, war, settler colonialism, and other forms of violence. Consider the more than 50 million children who have been displaced from their homes by dangerous conflicts, climate change, poverty, and instability in the wake of pandemics. Whether living as refugees in camps, as migrants to nations often hostile to their arrival, as undocumented immigrants seeking safety, or without access to school, childcare, and other social services shut down in response to COVID-19, these children face and navigate incredible hardships.

Throughout history, young children have spoken truth to power and galvanized movements-and they continue do so today. For example, Autumn Peltier (Anishinaabe) has advocated for water and Indigenous rights since the age of 8, and for the last decade, 13-year-old Genesis Butler has lobbied for animal rights in California and around the world. We know that young children are already engaged in dreaming and sharing ideas and conversations with each other and with adults. We see and hear children's everyday bravery to examine the injustices they face now and to imagine more just systems to come. Whether large-scale, global efforts or minute-to-minute acts of fairness and care, young children's capacities for resilience, empathy, and creativity are the inspiration for the work we share in The Critical Social Educator.

What can and what should educators of young children do to foster such thinking and action? How do teachers and caregivers respond to crises in creative ways? How can we support young people experiencing these and other atrocities through our curriculum, pedagogy, school policies, and activism? How can and how should we center and validate the communities that continue to be dehumanized and denigrated? How can and how should we support all young people, leveraging their power and energy to work toward a more just, more humane, more sustainable world?

Frustratingly, we know that educators of young children face enormous obstacles in their attempts to answer these questions. There are serious resource constraints that disproportionately affect schools 
serving Black, Indigenous, and People of Color as well as families in poverty. There are pressures to teach for high stakes standardized tests, meet vacuous content standards, and use problematic curriculum propagated by a neoliberal agenda. There are ideological challenges fueled by concerns of colleagues, administrators, and parents that young children ought to be kept sheltered from the world with the belief that school should be an apolitical or neutral "safe" space where "kids can be kids." There is a lack of professional development opportunities and preparation programs that ready educators to respond to these questions in thoughtful and skillful ways.

Despite all of this, we know that there are courageous colleagues across the globe who are engaged in innovative, impactful teaching and learning with young learners. We know there are educators unafraid to initiate necessary conversations about power, oppression, belonging, race, religion, gender, sexuality, and immigration with the inquisitive youth with whom they work and learn. We know there are educators, in formal and informal learning spaces, who are committed to the cultivation of strong community relationships and pedagogies that, as Django Paris (2012) argues, "support young people in sustaining the cultural and linguistic competence of their communities while simultaneously offering access to dominant cultural competence" (p. 95). We know there are teachers and school leaders who take up this work audaciously, firm in their convictions that all children deserve opportunities to learn and flourish in settings that value and honor their full selves. We know there are educational spaces determined to disrupt the school-to-prison nexus with great intention by refusing a culture of punishment and embracing restorative and transformative justice. We know there are educators dedicated to creating anti-racist, anti-oppressive, anti-imperialist, and/or anti-colonial opportunities for young children to learn about the world around them and to support them as they engage in their communities as agents of change.

The Critical Social Educator emerged from a group of educators frustrated by the limitations of traditional scholarly and practitioner journals. We saw a need for a space to highlight critical approaches to elementary and early childhood education and to make that space accessible to practitioners and researchers alike. At The Critical Social Educator, we commit to the following guiding principles:

A Critical Stance: We are informed by critical theories and are unapologetically oriented towards social justice and equity.

Centering Problems of Practice: We will foreground the problems of practice that are capturing teachers' and students' attention.

Attention to Social Issues: We will highlight a range of social issues, particularly those that educators of young children wrestle with and young children are experiencing.

Collaborative: We will intentionally assemble a group of educators with diverse identities (e.g., race, ethnicity, religion, etc.) and professional expertise (e.g., teachers, scholars, activists, etc.) to inform the journal's content and direction.

While many of us who worked in the creation of this journal work in the field of social studies education, we deliberately avoided the phrase "social studies" in deciding on a name for this journal. Often, identifying a disciplinary content area results in the perpetuation of intellectual silos-we do not want 
to constrain contributing authors to particular content areas and recognize the interdisciplinary nature of educating young children. Social education occurs in and outside of traditional content areas and classrooms - social education exists in the hallways, cafeteria, playground, school busses, bathrooms, after-school programs, and more. In fact, teachers and schools are always socially educating students in some fashion, whether these actions are conscious or not.

In an effort to create a journal that honors traditional academic writing, the authentic expertise of classroom teachers and other educators, and the voices of learners, The Critical Social Educator is committed to a peer review process that supports reviewers and authors in their work to create powerful scholarship for elementary social education. This commitment requires a shared responsibility to an open process whereby we critique manuscripts with care in order to lift each other and the field of education as a whole. Rather than leave the decision-making process to a single editor, our peer review process will consist, as we grow in numbers of colleagues similarly committed to this style of publishing, of multiple collectives that address the various parts of the publishing pipeline.

This inaugural issue features five articles wrestling with what it means to be a critical social educator. In their article centering pre-service teachers, Christine Rogers Stanton and Hailey Hancock (2021) share how they used PhotoVoice as an avenue to examine their students' developing identities and relationships to teaching social studies content. In their piece grounded in critical global education, Gerardo J. Aponte-Safe and Hanadi Shatara (2021) share an in-depth analysis of state-level standards to demonstrate how educators can bring global perspectives into their elementary social studies classrooms. Cassie Brownell and Anam Rashid (2021) unpack how a white, critical social educator provided children with the opportunity to engage in critical conversations around race using children's literature. Similarly, Mary Adu-Gyamfi, Angie Zapata, and Sarah Reid (2021) richly describe how picturebooks provide an avenue for teachers to engage in critical discussions around race and racism with young students. In the final article, Ryan Oto, Ngan Nguyen, Megan Custer, Peder Ericson, and Nick Liebelt (2021) emphasize how building and strengthening a small teacher collective committed to critical practices is essential to sustaining critical social education in classroom teaching.

The authors in The Critical Social Educator's first issue bravely engage in critical work with young children, classroom teachers, pre-service teachers, and curriculum. We want to thank these authors not only for their wonderful ideas but for their patience and support during the process of shepherding the inaugural issue to publication. Not unlike the process of translating a lesson plan on paper into action, we thank the authors for trusting us to travel on this journey where we often figured out how our open review and editing process would work while in the moment. It was incredibly eye-opening for all of us to participate in reviewing and editing in the open, corresponding with authors across various platforms (Google Docs, emails, Zoom, phone) to move the articles to the final versions you will soon read. As contributing author Ryan Oto reflected, "The reviewing process was so meaningful and an authentic learning experience. Having the chance to sit with the editors, hear their thoughts, and share our perspectives as authors offered more growth as a writer than I could have imagined." Dr. Christine Rogers Stanton additionally shared, 
As a scholar with a decade of publishing experience, I found working with The Critical Social Educator team to be refreshing and re-energizing. In most cases, when I've submitted a manuscript, there is a lengthy period of silence, followed by often contradictory comments from reviewers and a request to make extensive revisions in an unfairly short period of time. The Critical Social Educator's approach prioritizes professional dialogue, transparency, and growth, which can be particularly helpful in terms of work that strives to be innovative and/or focuses on a highly specialized topic or narrow context. This opportunity was also a powerful experience for my co-author, who was a doctoral candidate when we started the process. The editorial team provided mentoring and encouragement for us both through the use of questions, audiovisual conferencing, and thoughtful emails. This is the first journal publication where I have felt a part of the process and the team.

A special note of appreciation to $6^{\text {th }}$ grade student Jaquelin Fernandez Zepeda for her tremendous artwork depicting raised fists of solidarity amidst a field of flowers. We are beyond honored to have her piece grace the cover of our inaugural issue and look forward to more youth submissions.

Lastly, we wish to thank you, our first readers, for turning the digital pages of this inaugural issue. It is an honor to share this moment with you. Creating The Critical Social Educator is not an experience we take lightly. We fully embrace the responsibility to continue building a journal where we can all be heard, where we all can feel valued, and where we all can continue to learn.

In solidarity,

TCSE Editorial Collective, Spring 2021 ${ }^{1,2}$

Notes

1. To honor the supportive, collaborative process we seek to foster at The Critical Social Educator, we will "author" our work under a collective name. Members of the TCSE Editorial Collective, Spring 2021 include Noreen Naseem Rodríguez (lowa State University), Katy Swalwell (lowa State University), Sarah B. Shear (University of Washington-Bothell), Katie Payne (The University of Texas at Austin), Sarah Pamperin (lowa State University), Carla Shalaby (University of Michigan)

2. Article DOI: https://doi.org/10.31274/tcse.12469

\section{References}

Adu-Gyamfi, M., Zapata, A., \& Reid, S. (2021). "Who was scared?": Entering into reflections towards change as critical social educators. The Critical Social Educator, 1(1), 1-13. https://doi.org/10.31274/tcse.1131 
Aponte-Safe, G.J., \& Shatara, H. (2021). Realities and possibilities: Critical global education in Wisconsin elementary social studies standards. The Critical Social Educator, 1(1), 1-16. https://doi.org/10.31274/tcse.11480

Brownell, C., \& Rashid, A. (2021). Reading beyond the book: Examining a critical social educator's race and equity read-aloud in an early childhood classroom. The Critical Social Educator, 1(1), 1-14. https://doi.org/10.31274/tcse.11530

Oto, R., Nguyen, N., Custer, M., Ericson, P., \& Liebelt, N. (2021). Becoming a critical social educator: The power of a collective to counteract copy room conversations. The Critical Social Educator, 1(1), 1-12. https://doi.org/1031274/tcse.11520

Stanton, C.R., \& Hancock, H. (2021). "I'd say I have a bit of work to do": Exploring elementary social studies pre-service teacher criticality through photovoice. The Critical Social Educator, 1(1), 126. https://doi.org/10.31274/tcse.11524

Montoya-Galvez, C. \& Kates, G. (2019). Trump administration to detain migrant families and children for far longer with new rule. CBS News. Retrieved from https://www.cbsnews.com/news/migrantdetention-trump-administration-to-detain-migrant-families-and-children-for-far-longer-withnew-rule-2019-08-21/.

Paris, D. (2012). Culturally sustaining pedagogy: A needed change in stance, terminology, and practice. Educational Researcher, 41(3), 93-97.

Sands, G. (2019, March 27). Almost 40,000 children will be taken into federal custody this month, US border official says. CNN. Retrieved from https://www.cnn.com/2019/03/27/politics/immigration-border-40000-children/index.html. 